\title{
Effect of Leakage in Electrohydraulic Servo Systems Based on Complex Nonlinear Mathematical Model and Experimental Results
}

\author{
Attila Kovari \\ College of Dunaújváros, Táncsics M. 1/A, 2400 Dunaújváros, Hungary \\ kovari@mail.duf.hu
}

\begin{abstract}
This paper looks into the background of the internal leakage effect on the dynamic behavior of an electrohydraulic servo positioning system. The electrohydraulic servo systems are widely used in precise control at high forces, but the overall quality of this servo control could be impaired by faults in the system. There could be several defects which have effect on the system response, but this work points to the effect of internal leakage of the hydraulic cylinder because this error cannot be easily detected. To show the effect of internal leakage on electrohydraulic servo system a complex nonlinear mathematical model considering the leakage of the hydraulic cylinder is used. The work herin demonstrates the relationship between internal leakage and the dynamic behaviour of the servo positioning system. Laboratory test results are used to verify the conclusions drawn from the mathematical model of the complete servo positioning system.
\end{abstract}

Keywords: servo system; mechatronics; position control; hydraulic servo; leakage

\section{Introduction}

In control technology, several uses of servo systems can be found, among which the most common applications are motion/rotation speed or position control [1]. Servo systems are mainly used when the advantages of these systems can be exploited to set the technological parameters of the controlled process: higher precision, reliability, better repeatability, shorter settling time, coordinated movement (even more in case of more degrees of freedom) [2], [3]. The advantages previously mentioned can be achieved by precise and appropriate control of technological equipment. In the case of precise and fast control, such as manufacturing equipment, mouldering equipment, mobile machines, material handling equipment and so on, servo systems are widely used [4].

The electrohydraulic servo systems can be applied in various ways in the referred fields, including testing equipment, active shock absorbers, mining machinery, material testing equipment, airplane simulators, paper manufacturing machines, 
hydraulic systems on ships, robotics as well as steel and aluminum rolling mills, etc. Hydraulic actuators are widely used in the industrial environment due to their large reaction force on heavy loads, large power/volume ratio, good dynamic behavior, adequate rigidity, good heat removal, simple protection against overload, resistance against exterior impacts and also such actuators can be started under load with maximum acting power [5]. Hydraulic systems are also widely applied on airplanes where the application of hydraulic actuators is an ideal choice because of their large power/weight ratio and precise controllability [5].

The theoretical background and the elements of servo hydraulic systems are introduced in different studies [4]-[12], [23]-[25]. Generally, every regulated hydrostatic drive can be regarded as a hydraulic servo that is a closed loop system and in which the controlled feature of the drive is controlled by the application of some hydraulic element. In case of hydraulic systems, the servo mechanism usually controls large power units with low energy input signal. In the servo system, the servo hydraulic actuator corrects the output signal of the system by negative feedback based on the difference between the reference and real output signal, as well as it amplifies the acting power [7].

In modern hydraulic systems, more types of electromagnetically operated controlling units are used to implement electrohydraulic control. In precise servo technology valves are used and the valve spool operated by proportional magnets or electromagnet adjusted flapper ensures more precise operation [10], [12].

The block diagram of a typical electrohydraulic position control servo system can be seen in Fig. 1.

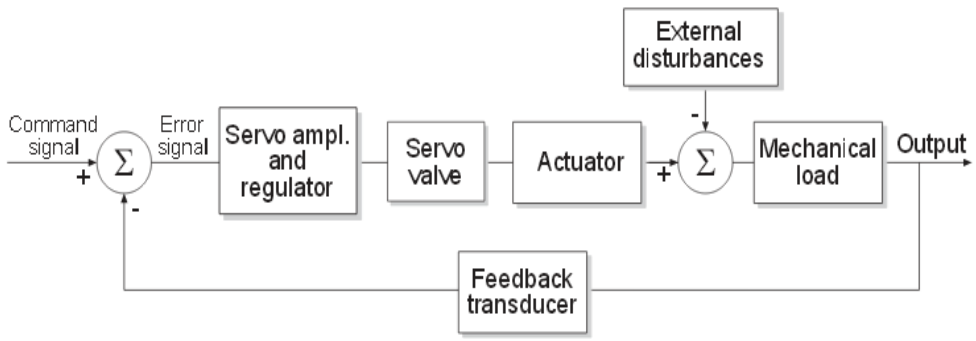

Figure 1

Typical hydraulic servo system

The control quality of hydraulic servo systems depends on the main elements used such as: servo regulator/controller, servo valve, hydraulic cylinder/actuator, feedback position transducer and power supply. The dynamic response of the system mainly builds upon the frequency characteristic of servo valve and load, but this overall quality of servo control could be impaired by faults in the system. There could be several defects which affect the system response. This study points to the effect of internal leakage of the hydraulic cylinders, since this defect and consequently the replacement or refurbishment of the actuator, can cause a longer 
downtime of the equipment. This downtime may cause a greater loss of production and revenue in the case of continuously operated manufacturing equipment, for example a hot rolling mill. The fault of internal leakage is caused by wrong wear of piston seal or abrasion. This seal prevents the leakage and closes the gap between piston and the cylinder wall. External leakage can be detected visually, so this leakage can be easily perceived [21]. The internal leakage cannot be detected easily until the actuator seal is almost completely damaged, due to this reason the detection of internal leakage is more important. Several complex models based on the fault detection method are applied for electrohydraulic servo systems, but the leakage is not examined in details by the applied models [13]-[20].

This paper looks into the background effect of the leakage by a complex nonlinear mathematical model and demonstrates the relationship of internal leakage on dynamic behavior of the servo positioning system. Experimental results are presented to verify the conclusions drawn from the model.

\section{Electrohydraulic Servo Positioning System}

The examined equipment is a hydraulic positioning system which consists of a hydraulic power supply with relief valve and accumulator, flow control servo valve, a linear actuator unit (hydraulic cylinder), a position sensor and an electronic controller unit. The output signal of the system is the electric signal of the position transducer which is proportional with the actuator position. The servo amplifier and controlling unit determine the control signal of the servo valve based on the error signal that shows the difference between the reference and the actual output signal. The servo valve modifies the oil flow of the hydraulic cylinder until it is in appropriate position; I. e. the error signal is zero. Proportional or nozzle-flapper based servo valves are used in general hydraulic servo positioning systems depending on their applications. A simple servo valve controlled positioning system can be seen in Figure 2.

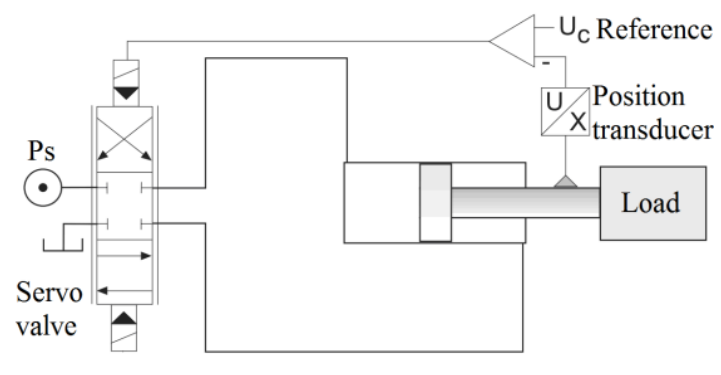

Figure 2

Servo valve controlled hydraulic cylinder 
A complete servo hydraulic positioning system with accumulator, relief valve, asymmetric hydraulic cylinder, mass-spring-dumper load and sensors is shown in Figure 3.

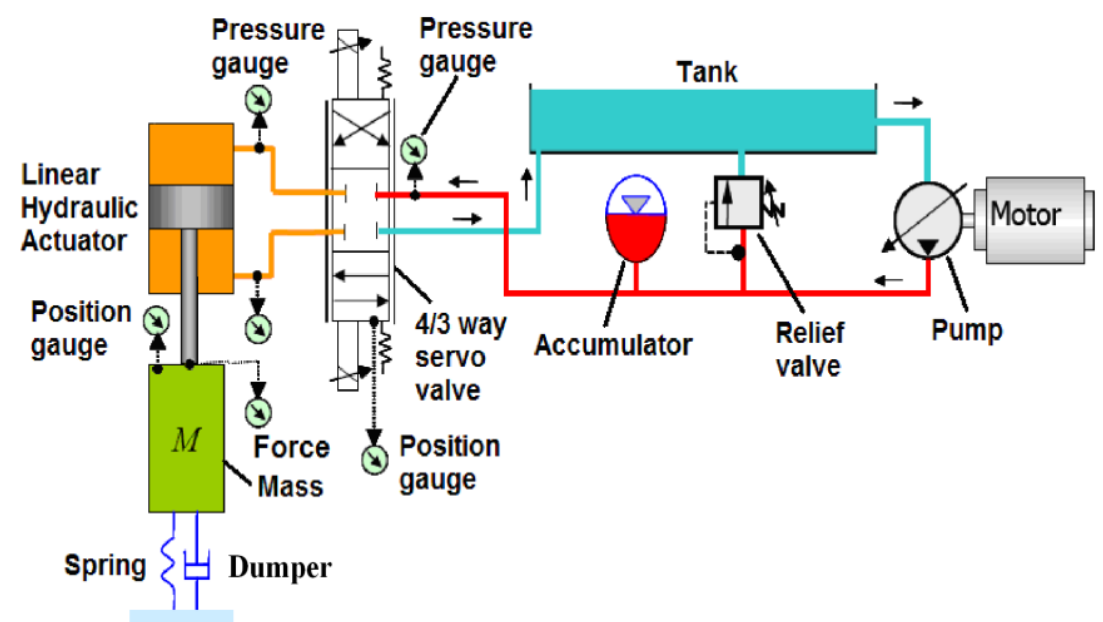

Figure 3

Electrohydraulic servo positioning system with mechanical load

\section{Mathematical Model of the Electrohydraulic Positioning System}

The electrohydraulic servo system was examined by a close-to-reality mathematical model, taking into account the non-linear and dynamic behaviour of hydraulic elements and the leakage of hydraulic actuator [16]-[20].

A servo-valve has high-order non-linear response and a number of valve parameters are required to calculate an accurate mathematical model [9]. The servo valve construction, models [10], specification standards [12], dynamic response model are described in detail in the literature [9], [17], the construction of torque motor and valve sleeve can be seen in Figure 4 and 5. The torque motor consists of an armature moved sleeve pivot. When current flows in the armature coils, the armature ends rotate because of the torque generated by the magnet fields of the current. This movement changes the oil flow of opposing nozzles, because the differential pressure of spool changes, therefore the spool is moved inside the valve sleeve shown in Figure 5. 


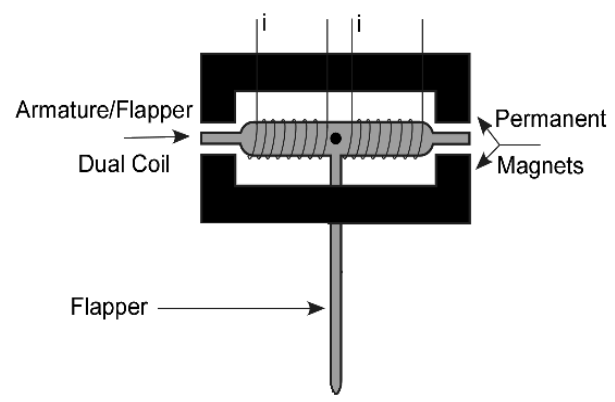

Figure 4

Servo-valve torque motor

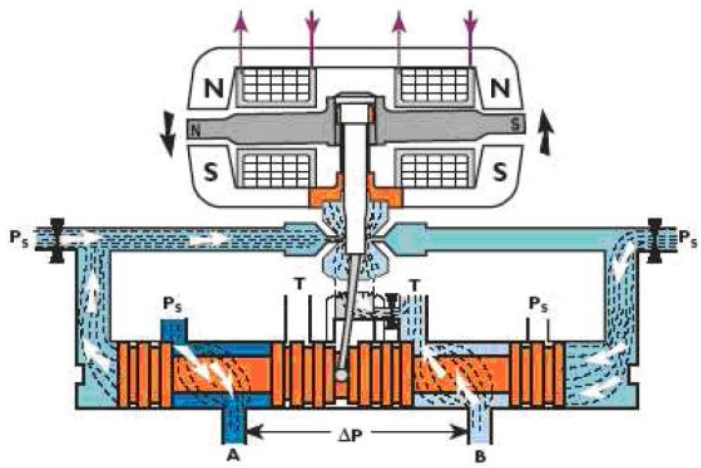

Figure 5

Spool movement inside the valve sleeve

When the spool moves from centre position the nozzles open the oil flow between the pressure port and tank port ( $\mathrm{P}$ and $\mathrm{T})$, and the two control ports ( $\mathrm{A}$ and $\mathrm{B})$, so the actuator is operated by the pressured oil (Figs. 6 and 7). In most cases a second order linear model of servo-valve can approximate the physical system properly [9]. The coefficients of second order system can be calculated by the frequency response based on Bode plots included in the servo-valve reference data [9], [22]. The torque motor of the servo-valve can be modeled as a series L-R circuit. The torque and consequently the moving force $F_{s}$ of the valve spool are proportional to the torque motor current, the approximation of dynamic model of the valve spool movement $x_{s}$ can be specified by a second order transfer function $\left(\omega_{s}\right.$ is the natural frequency and $\zeta_{s}$ is damping ratio of the spool, $k_{t}$ is proportionality coefficient) [9, 18]:

$$
\frac{d^{2} x_{s}}{d t^{2}}+2 \cdot \zeta_{s} \cdot \omega_{s} \cdot \frac{d x_{s}}{d t}+\omega_{s}^{2} \cdot x_{s}=\omega_{s}^{2} \cdot k_{t} \cdot i
$$


The oil flow rate at the control ports also depends on the pressure drop across the valve. The As flow cross-section is proportional (factor is $w$ ) to the valve spool displacement (Fig. 6).

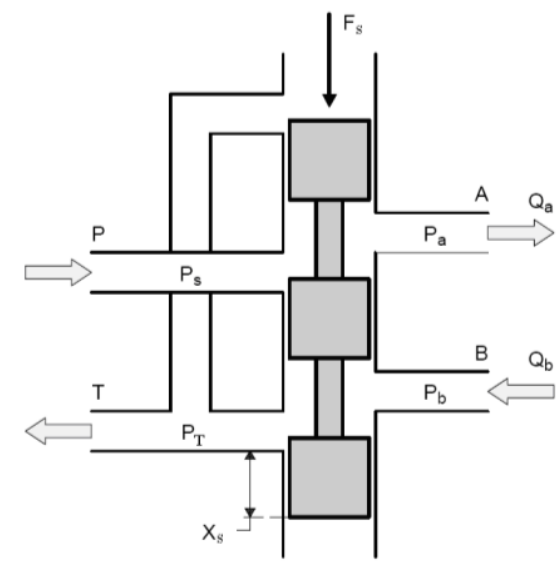

Figure 6

4/3 Flow control valve (Three Land, Four-way)

$\mathrm{P}_{\mathrm{S}}, \mathrm{P}_{\mathrm{T}}$ : supply and tank pressure; $P_{a}, P_{b}$ : actuator chamber pressures; $Q_{a}, Q_{b}$ : actuator oil flows

The oil flow is also proportional to the square root of the pressure drop and $c_{s}$ is the volumetric flow coefficient ( $\rho$ volumetric density of the oil) [7], [17], [18]:

$Q=c_{s} \cdot w \cdot x_{s} \cdot \sqrt{\frac{2}{\rho} \cdot \Delta P}$

A $c_{s} \cdot w$ product can be approximated by the valve nominal pressure drop $\Delta P_{N}$ and flow $Q_{N}[10]$ :

$C=c_{s} \cdot w=\frac{Q_{N}}{\sqrt{0,5 \cdot \Delta P_{N}}}$

The compressibility of the oil creates a "spring" effect in the cylinder chambers which interacts with the piston mass to give a low frequency resonance. The effect can be modeled using the flow continuity equation from fluid mechanics [6] $\left(\rho_{a}\right.$ and $\rho_{b}$ the density of the oil in chamber "a" and "b", $Q_{a}$ and $Q_{b}$ the load and return flow of the valve):

$$
\frac{d}{d t}(\rho \cdot V)=m_{a}-m_{b}=\rho_{a} \cdot Q_{a}-\rho_{b} \cdot Q_{b}
$$

In case of constant oil density the formula is:

$$
Q_{a}-Q_{b}=\frac{d V}{d t}+\frac{V}{\rho} \cdot \frac{d}{d t}
$$


Using the $\beta$ fluid bulk modulus (mineral oils have $1.410^{9} \mathrm{~N} / \mathrm{m}$, the value is pressure dependent) the formula can be written as [17], [18]:

$\frac{d \rho}{\rho}=\frac{d P}{\beta}$

$Q_{a}-Q_{b}=\frac{d V}{d t}+\frac{V}{\beta} \cdot \frac{d P}{d t}$

where $V$ is the internal fluid volume. The pressure in cylinder chambers can be calculated using the $A_{a}, A_{b}$ active areas of the piston annulus and $V_{a}, V_{b}$ internal oil volume in chamber "a" and "b", $x_{d}, v_{d}$ position:

$$
\begin{aligned}
& \frac{d P_{a}}{d t}=\frac{\beta}{V_{a}} \cdot\left(Q_{a}-\frac{d V_{a}}{d t}\right) \\
& \frac{d P_{b}}{d t}=\frac{\beta}{V_{b}} \cdot\left(-Q_{b}-\frac{d V_{b}}{d t}\right)
\end{aligned}
$$

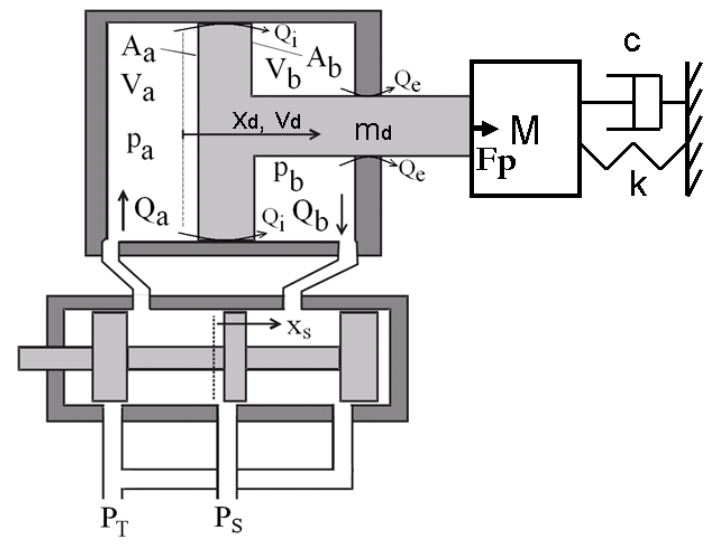

Figure 7

Hydraulic cylinder with 4/3 servo valve and mass-spring-dumper load

Using Merrit's laminar flow leakage model [10], the internal leakage oil flow at piston $Q_{i}$ and external leakage oil flow at piston $\operatorname{rod} Q_{e}$ (see Fig. 7) can be modeled by the leakage resistance. The formula of leakage model using $R_{i}$ and $R_{e}$ the internal and external cylinder's leakage resistance or $C_{i}$ and $C_{e}$ the internal and external cylinder's leakage coefficient [17], [18]:

$$
\begin{aligned}
& Q_{i}=\frac{P_{a}-P_{b}}{R_{i}}=C_{i}\left(P_{a}-P_{b}\right) \\
& Q_{e}=\frac{P_{b}}{R_{e}}=C_{e} \cdot P_{b}
\end{aligned}
$$


The chamber's pressure values can be written as:

$$
\begin{aligned}
& \frac{d P_{a}}{d t}=\frac{\beta}{V_{a}} \cdot\left(Q_{a}-\frac{d V_{a}}{d t}-Q_{i}\right) \\
& \frac{d P_{b}}{d t}=\frac{\beta}{V_{b}} \cdot\left(-Q_{b}-\frac{d V_{b}}{d t}+Q_{i}-Q_{e}\right)
\end{aligned}
$$

The net acting force $F_{P}$ can be calculated by the pressure and annuluses values of the two sides of the piston:

$$
F_{P}=P_{a} \cdot A_{a}-P_{b} \cdot A_{b}
$$

Based on (12-14) the acting force is:

$$
\begin{aligned}
& F_{P}=\int\left\{\frac{\beta}{V_{a}} \cdot\left(Q_{a}-A_{a} \cdot v_{d}-Q_{i}\right)\right\} d t \cdot A_{a}- \\
& -\int\left\{\frac{\beta}{V_{b}} \cdot\left(-Q_{b}+A_{b} \cdot v_{d}+Q_{i}-Q_{e}\right)\right\} d t \cdot A_{b} \\
& F_{P}(t)=\int_{0}^{t}\left(\frac{\beta \cdot A_{a}}{V_{a 0}+A_{a} \cdot x_{d}(\tau)} \cdot Q_{a}(\tau)+\frac{\beta \cdot A_{b}}{V_{b 0}-A_{b} \cdot x_{d}(\tau)} \cdot Q_{b}(\tau)\right) d \tau \\
& -\int_{0}^{t}\left(\left[\frac{\beta \cdot A_{a}^{2}}{V_{a 0}+A_{a} \cdot x_{d}(\tau)}+\frac{\beta \cdot A_{b}^{2}}{V_{a 0}+A_{b} \cdot x_{d}(\tau)}\right] \cdot v_{d}(\tau)\right) d \tau \\
& -\int_{0}^{t}\left(\left[\frac{\beta \cdot A_{a}}{V_{a 0}+A_{a} \cdot x_{d}(\tau)}+\frac{\beta \cdot A_{b}}{V_{b 0}+A_{b} \cdot x_{d}(\tau)}\right] \cdot \frac{P_{a}(\tau)-P_{b}(\tau)}{R_{i}}\right) d \tau \\
& -\int_{0}^{t}\left(\frac{\beta \cdot A_{b}}{V_{b 0}+A_{b} \cdot x_{d}(\tau)} \cdot \frac{P_{b}(\tau)}{R_{e}}\right) d \tau
\end{aligned}
$$

The position of the piston can be calculated by the acting force and the load. In case of a mass $M$ (mass of piston $m_{d}$ ) - spring $k$ - dumper $c$ load and friction $F_{s}$, the movement of the system is:

$$
\left(M+m_{d}\right) \cdot \frac{d^{2} x_{d}(t)}{d t^{2}}+c \cdot \frac{d x_{d}(t)}{d t}+k \cdot x_{d}(t)=F_{P}(t)-\operatorname{sgn}\left(v_{d}\right) \cdot F_{s}
$$

The complete nonlinear state space model of the electrohydraulic positioning system is: 


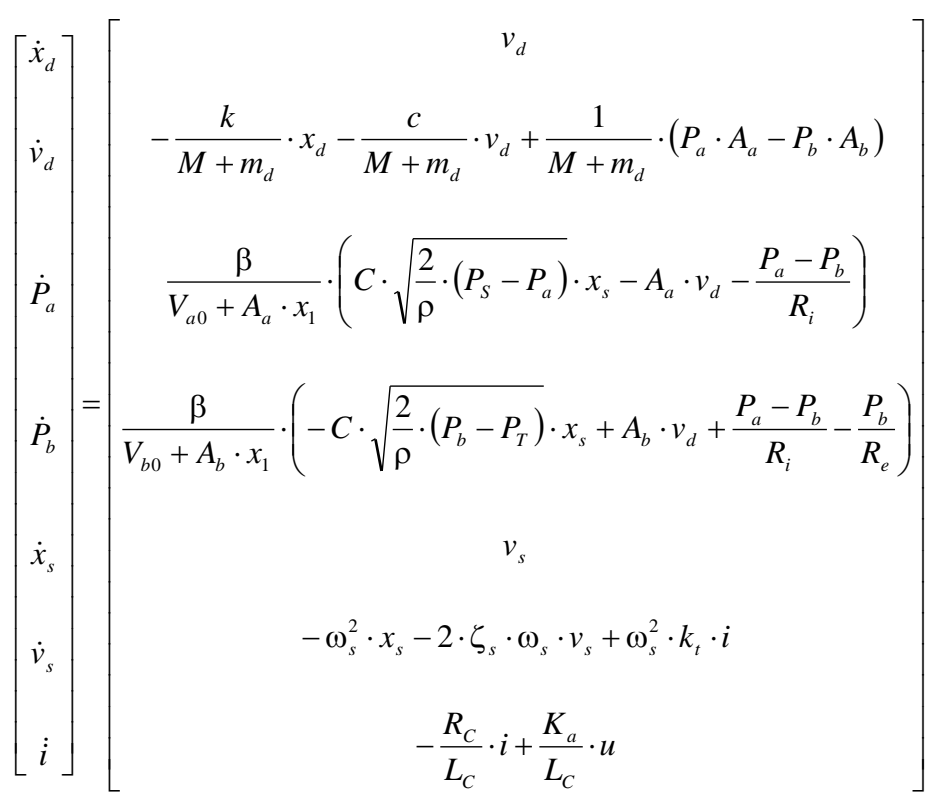

This state space model can be used to examine the effect of leakage that appears in hydraulic cylinder.

\section{Effect of Internal Leakage on Dynamic Performance}

In the case of a worn piston seal, the internal leakage causes an oil flow decrease in chamber "a" and an oil flow increase in chamber "b". The external leakage causes the oil to flow out of chamber " $b$ " and decreases the oil flow returning to the tank. The dynamic behavior of hydraulic positioning system depends on the pressure difference of hydraulic cylinder chambers and control force generated by these pressure values. Based on the nonlinear mathematical model of the electrohydraulic servo positioning system the following relation can be observed between the internal leakage resistance and chamber's pressure values:

$$
\begin{aligned}
& \frac{d P_{a}}{d t}=\frac{\beta}{V_{a}} \cdot\left(Q_{a}-\frac{d V_{a}}{d t}-\frac{P_{a}-P_{b}}{R_{i}}\right) \\
& \frac{d P_{b}}{d t}=\frac{\beta}{V_{b}} \cdot\left(-Q_{b}-\frac{d V_{b}}{d t}+\frac{P_{a}-P_{b}}{R_{i}}-\frac{P_{b}}{R_{e}}\right)
\end{aligned}
$$


The differential equations of chamber pressure values clearly show that, while the pressure difference $P a-P b$ of chambers is low, the effect of internal leakage is negligible as well. When the pressure difference and consequently the net acting force starts to increasing, the internal leakage oil flow also increases [22]. This greater leakage, decreases the pressure alteration speed in chamber "a" according to Eq. (19):

$\left(\frac{d P_{a}}{d t}\right)=\frac{\beta}{V_{a}} \cdot\left(Q_{a}-\frac{d V_{a}}{d t}\left(-\frac{P_{a}-P_{b}}{R_{i}}\right)\right.$

This greater internal leakage causes contrary effect in chamber "b" based on Eq. (20):

$\frac{d P_{b}}{d t}=\frac{\beta}{V_{b}} \cdot\left(-Q_{b}-\frac{d V_{b}}{d t}\left(+\frac{P_{a}-P_{b}}{R_{i}}\right)-\frac{P_{b}}{R_{e}}\right)$

The internal leakage modifies the acting force dynamic through its effect on chamber's pressure values. According to Eq. (14) the differential formula of the acting force can be written as:

$$
\frac{d F}{d t}=\frac{d P_{a}}{d t} \cdot A_{a}-\frac{d P_{b}}{d t} \cdot A_{b}
$$

Based on this formula, it is recognized that the pressure alteration speed in chamber "a" decreases while, on the opposite side, in chamber "b", this speed increases, resulting in the overall decrease of the acting force alteration speed. These effects impair the dynamic controllability of the acting force. Differential equation of the acting force:

$$
\begin{aligned}
& \left(\frac{d F(t)}{d t}\right)=\left(\frac{\beta \cdot A_{a}}{V_{a 0}+A_{a} \cdot x(t)} \cdot Q_{a}(t)+\frac{\beta \cdot A_{b}}{V_{b 0}-A_{b} \cdot x(t)} \cdot Q_{b}(t)\right) \\
& -\left(\left[\frac{\beta \cdot A_{a}^{2}}{V_{a 0}+A_{a} \cdot x(t)}+\frac{\beta \cdot A_{b}^{2}}{V_{a 0}+A_{b} x(t)}\right] \cdot v(t)\right] \\
& +\left(\frac{\beta \cdot A_{a}}{V_{a 0}+A_{1} \cdot x(t)}+\frac{\beta \cdot A_{b}}{V_{b 0}+A_{b} \cdot x(t)}\right] \cdot \frac{P_{a}-P_{b}}{R_{i}}
\end{aligned}
$$

The complex mathematical formula of acting force shows the effects of each factor. The third part of this form describes the negative effects of internal leakage. Based on this negative effect of internal leakage, the control speed of acting force decreases, this impacts the acceleration of mechanical system adversely. This decelerating factor causes a damping effect in the dynamic response of this positioning system. 


\section{Experimental Results}

The Laboratory electrohydraulic test system at Óbuda University Donát Bánki Faculty of Mechanical and Safety Engineering, was used to examine the leakage effect on the behaviour of this hydraulic positioning system. The laboratory test hydraulic system and computer-aided control and data acquisition unit are shown in Figures 8-10.

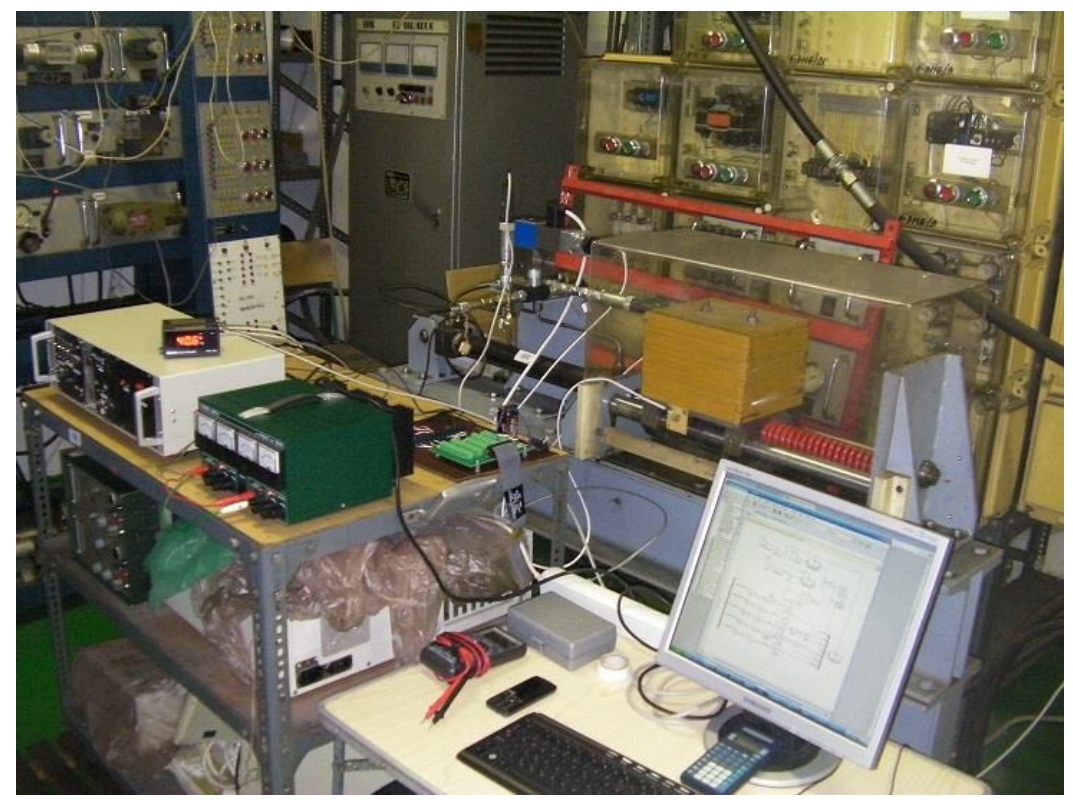

Figure 8

Electrohydraulic positioning system and computer control 


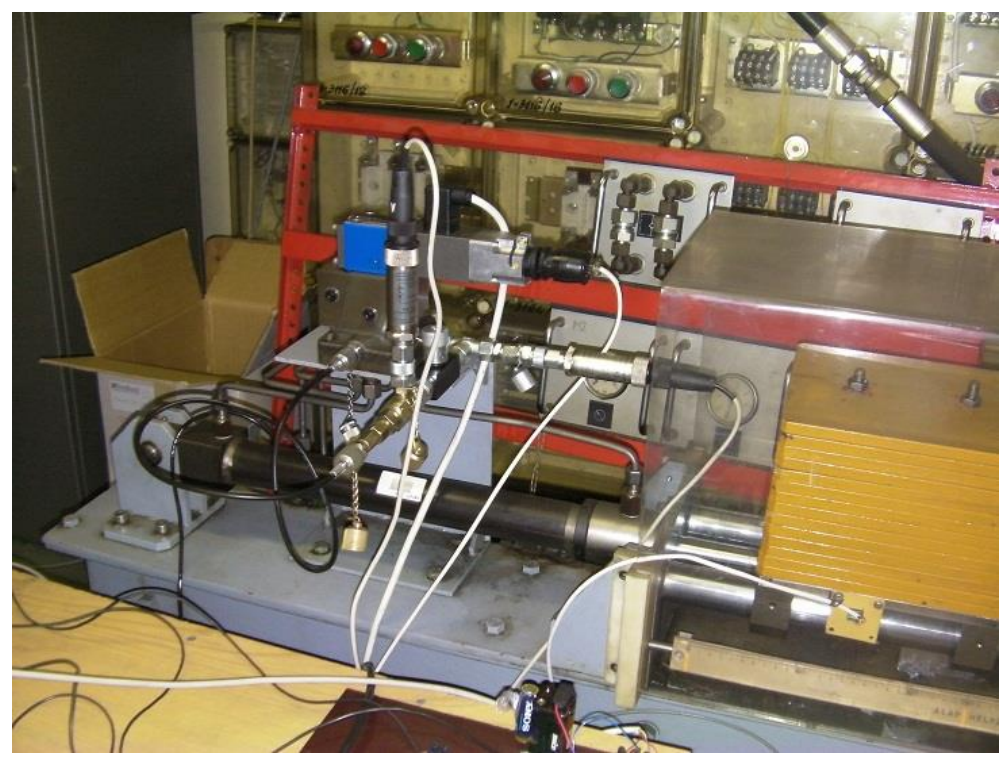

Figure 9

Hydraulic cylinder and proportional valve with pressure transducers

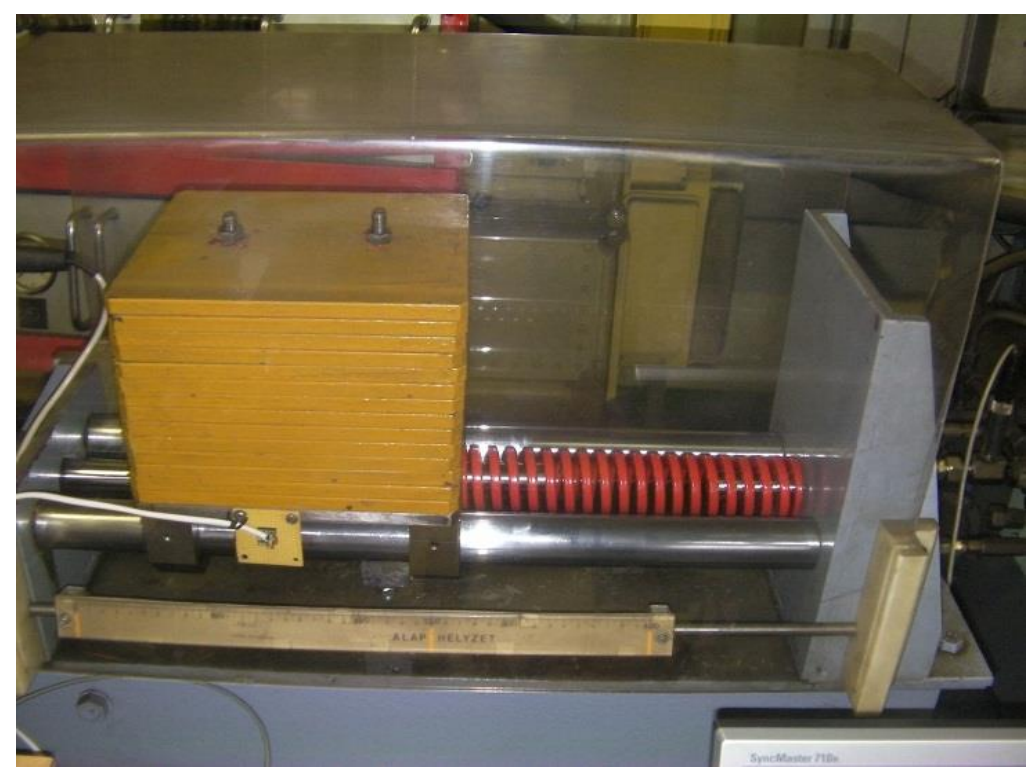

Figure 10

Mass-spring mechanical load of the positioning system 
The hydraulic circuit diagram of the electrohydraulic test positioning system is shown in Figure 11.

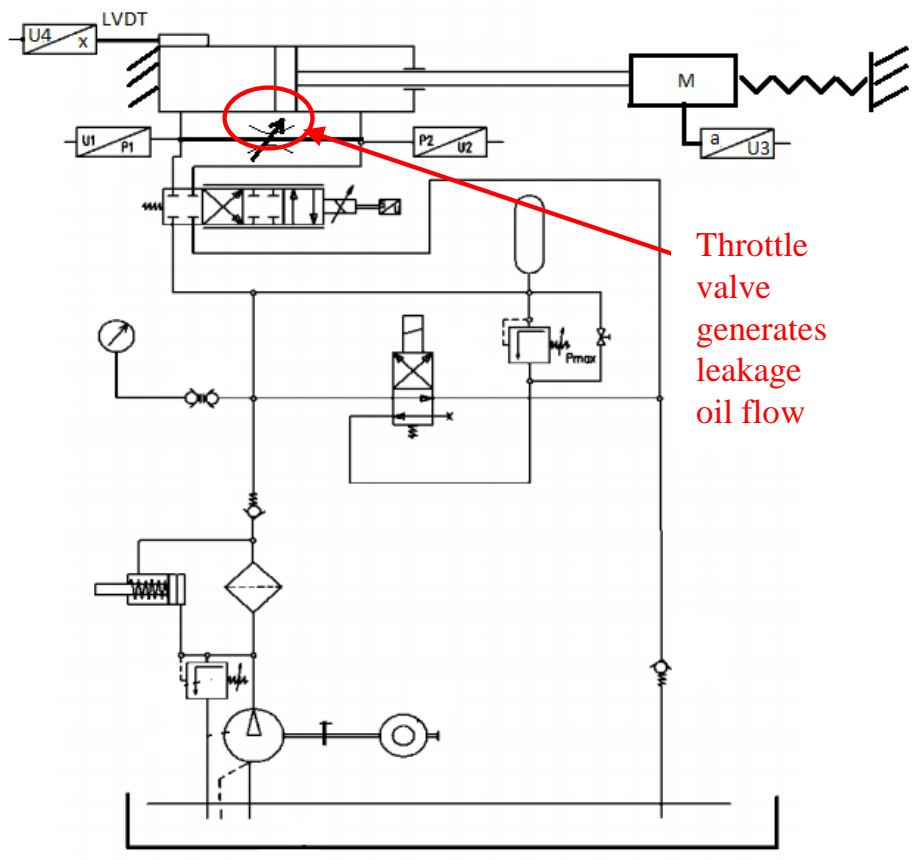

Figure 11

Hydraulic circuit diagram of the electrohydraulic positioning system

Parameters of the positioning system are included in Table I.

Table 1

Contains the result of comparing in pairs with the final result

\begin{tabular}{|c|c|c|}
\hline Component & Type & Main parameter \\
\hline $\begin{array}{c}\text { Asymmetric, double } \\
\text { acting hydraulic } \\
\text { cylinder }\end{array}$ & $\begin{array}{c}\text { Hagenbuch AG } \\
\text { KWS 40/28 - 400 }\end{array}$ & $\begin{array}{c}\mathrm{L}=400 \mathrm{~mm} \\
\mathrm{D}=40 \mathrm{~mm}^{2} \\
\mathrm{~d}=28 \mathrm{~mm}^{2} \\
\text { Pos.: I: } 4 \ldots 20 \mathrm{~mA}\end{array}$ \\
\hline $\begin{array}{c}\text { Bosch servo valve } \\
\text { with linear magnet }\end{array}$ & $\begin{array}{c}\text { 4WRP H6C4B 10L } \\
\text { 1X/G24Z4/M } \\
\text { 0 811 404 112 }\end{array}$ & $\begin{array}{c}\text { Pmax }=250 \mathrm{bar} \\
\text { Qn: } 10 \mathrm{l} / \mathrm{min}(\Delta \mathrm{P}=70 \mathrm{bar})\end{array}$ \\
\hline Bosch valve drive & RV45 $10 \mathrm{~V}$ & $\mathrm{U}:-10 \ldots 10 \mathrm{~V}$ \\
\hline Pump & $\begin{array}{c}\text { Hydromatik GmbH } \\
\text { A2F 10 R4P1 }\end{array}$ & $\mathrm{Vg}=9,4 \mathrm{ml} / \mathrm{rot}$ \\
\hline Accumulator & $\begin{array}{c}\text { Hydac FAB NR 3 } \\
\text { 226 C 27198 1L }\end{array}$ & $\mathrm{V}=11$ \\
\hline $\begin{array}{c}\text { Precision throttle } \\
\text { valve }\end{array}$ & Parker 9N600S4F & $\begin{array}{c}\mathrm{Qn}=301 / \mathrm{min} \\
\text { Amax }=0,22 \mathrm{~cm}\end{array}$ \\
\hline
\end{tabular}




\begin{tabular}{|c|c|c|}
\hline Pressure gauge 1 & $\begin{array}{l}\text { Hydac Druckfermer } \\
\text { Typ. } 905632 \\
\end{array}$ & $\begin{array}{l}\mathrm{P}=0 \ldots 100 \mathrm{bar} \\
\mathrm{Iki}=4 \ldots 20 \mathrm{~mA}\end{array}$ \\
\hline Pressure gauge 2 & $\begin{array}{l}\text { Hydac Druckfermer } \\
\text { Typ. } 905934\end{array}$ & $\begin{array}{l}\mathrm{P}=0 \ldots 400 \mathrm{bar} \\
\mathrm{Iki}=4 \ldots 20 \mathrm{~mA}\end{array}$ \\
\hline Accelerometer & Pololu MMA7341L & $\begin{array}{c}\mathrm{a}= \pm 3 / 11 \mathrm{~g} \\
\mathrm{E}=440 \mathrm{mV} / \mathrm{g}\end{array}$ \\
\hline Mass & - & $\mathrm{M}=60 \mathrm{~kg}$ \\
\hline Spring & $\begin{array}{c}\text { RECOM SZ } 8030 \\
50 \times 254\end{array}$ & $\begin{array}{c}\mathrm{D}_{\mathrm{h}}=50 \mathrm{~mm} \\
\mathrm{~L}_{0}=254 \mathrm{~mm} \\
\mathrm{k}=89 \mathrm{~N} / \mathrm{mm}\end{array}$ \\
\hline Hydraulic oil & $\begin{array}{l}\text { HIDROKOMOL P- } \\
46\end{array}$ & $\begin{array}{c}\rho=0,872 \mathrm{~g} / \mathrm{cm}^{3}\left(\mathrm{~T}=15^{\circ} \mathrm{C}\right) \\
v=46 \mathrm{~mm}^{2} / \mathrm{s}\left(\mathrm{T}=40^{\circ} \mathrm{C}\right)\end{array}$ \\
\hline
\end{tabular}

The internal leakage was generated by a precision adjustable throttle connected parallel with the hydraulic cylinder. An accelerometer provided usable information about the dynamic movement of the positioning system and pressure sensors are used to observe the pressure in actuator chambers.

The Bosch Rexroth industrial servo position controller was changed to a $\mathrm{PC}$ aided control with MATLAB and Real-Time Windows Target runtime environment for position control algorithm and National Instruments NI PCI6251 unit for data acquisition. The next figure (Fig. 12) shows the curves of observed displacement parameters in case of start-stop:

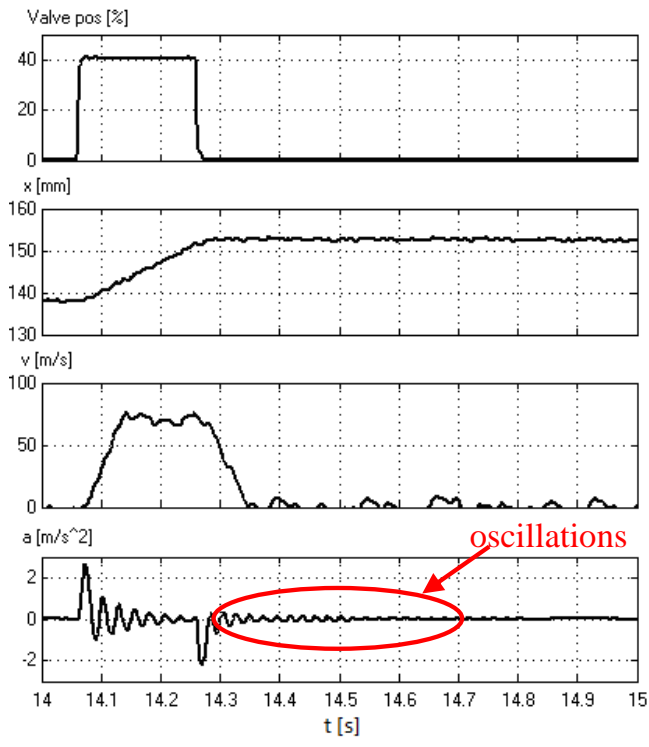

Figure 12

Observed displacement parameters of electrohydraulic positioning system 
The mechanical oscillations of the electrohydraulic servo system can be detected more accurately by the accelerometer signal. The oscillations were monitored at quick stop of the system at different throttle valve values, therefore at different leakage resistance [20]. The settling times $\left(\varepsilon_{a}=0,1 \mathrm{~m} / \mathrm{s}^{2}\right)$ were calculated and can be seen in Figure 13.

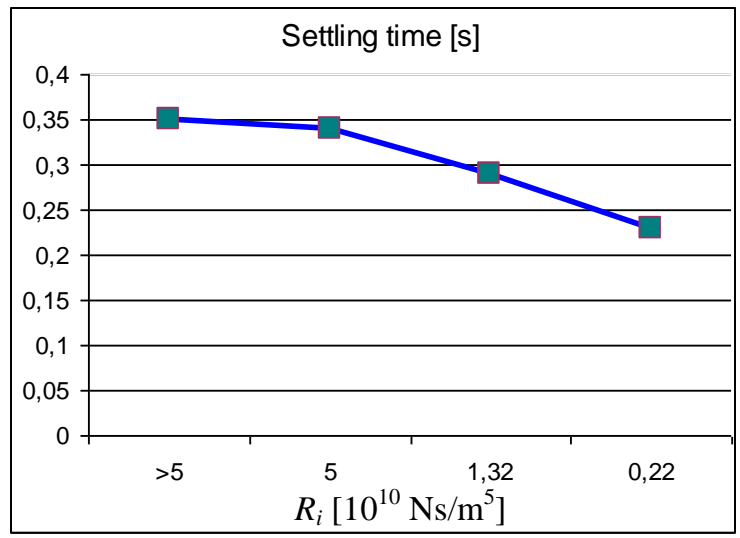

Figure 13

Settling time at different leakage resistance

The decelerating feature of the electrohydraulic servo positioning system at decreasing leakage resistance/increasing leakage oil flow can be seen in Figure 12. When the leakage oil flow increases the settling time of the system is reduced. This effect means that leakage causes a higher dumping factor of the electrohydraulic system.

\section{Discussion}

The results of an electrohydraulic servo system presented in this paper, can be observed from the point of effect of internal leakage. A complex nonlinear mathematical model was used to see into the background of the effect of internal leakage and how the dependency of the system dynamic response. Laboratory test verification presented in this paper was carried out to verify the conclusions drawn from the mathematical model of the electrohydraulic servo positioning system and the relation between internal leakage and dynamic behaviour of the system.

Based on the description and interpretation of the mathematical model, it can be concluded that the presented model can be adaptable in the design of leakage fault detection method for electrohydraulic servo systems. Early leakage detection could help in the planning of the preventive maintenance of servo hydraulic 
actuators, which is a very important aspect, in the case of a continuously working production unit.

\section{Conclusions}

In this paper, a detailed nonlinear complex mathematical model was presented for an electrohydraulic servo positioning system. This complex model includes the effects of leakage, based on Merrit's laminar flow leakage model. Using this mathematical representation of the electrohydraulic servo system, an obvious effect can be demonstrated between internal leakage oil flow and the chamber's pressure values and acting force of the hydraulic cylinder. It can be concluded that increased internal leakage causes a negative effect on the dynamic performance of the positioning system with an increased damping feature.

Experimental results of internal leakage were examined in the laboratory for hydraulic tests at Óbuda University Donát Bánki within the Faculty of Mechanical and Safety Engineering. Damping features of the system were observed by the calculated settling time of the system's oscillations. It can be seen that increased leakage leads to lower settling times in free oscillations of the system, because the system's damping effect is increased.

\section{References}

[1] Tan Kok Kiong, Andi Sudjana Putra: Drives and Control for Industrial Automation, Advances in Industrial Control, Springer-Verlag London, 2011

[2] George W. Younkin: Industrial Servo Control Systems: Fundamentals and Applications, Second Edition, Marcel Dekker Inc. New-York, 2003

[3] Hubert Maxwell James: Nathaniel B. Nicholas, Ralph Saul Phillips, Theory of Servomechanism, McGRAW-HILL Inc., 1947

[4] Philco Technological Institute: Servomechanism Fundamentals and Experiments, Prentice-Hall, 1964

[5] Karl-Erik R.: Hydraulic Servo Systems, Linköpings universitet, TMHP51, 2008

[6] Jelali M., Kroll A.: Hydraulic Servo-Systems, Modelling, Identification and Control, Springer-Verlag London, 2003

[7] Anderson W.:Controlling Electrohydraulic Systems, Marcel Dekker Inc. New-York, 1988

[8] Backe W.: The Present and Future of Fluid Power, Proceedings of the Institution of Mechanical Engineers, Part I: Journal of Systems and Control Engineering, Vol. 207, 1993, pp. 193-212

[9] Richard P.: DSP Control of Electro-Hydraulic Servo Actuators, Texas Instruments, 2005 
[10] Merritt, H. E.: Electro-Hydraulic Servo Valve Construction, Models and Use, Hydraulic Control Systems, John Wiley \& Sons, 1967

[11] Edvard D., Uros Z.: An Intelligent Electro-Hydraulic Servo Drive Positioning, Journal of Mechanical Engineering, Vol. 57, 2011, pp. 394404

[12] William J. T.: Specification Standards for Electrohydraulic Flow Control Servovalves, Technical Bulletin, Vol. 117, 1962

[13] Isermann R: Supervision, Fault-Detection and Fault-Diagnosis Methods an Introduction, Control Engineering Practice, Vol. 5, 1997, pp. 639-652

[14] Le T T, Watton J, Pham D T: Fault Classification of Fluid Power System Using a Dynamic Feature Extraction Technique and Neural Networks, Journal of System and Control Engineering, Vol. 211, 1998, pp. 307-317

[15] Shi Z, Gu F, Lennox B, Ball A D: The Development of an Adaptive Threshold for Model-based Fault Detection of a Nonlinear ElectroHydraulic System, Control Engineering Practice, Vol. 13, 2005 pp. 13571367

[16] Halnay A, Safta C A, Ursu I, Ursu F: Stability of Equilibria in a Fourdimensional Nonlinear Model of a Hydraulic Servomechanism, Journal of Engineering Mathematics, Volume 49, Number 4, 2004 pp. 391-405

[17] A. Kovari: Influence of Cylinder Leakage on Dynamic Behaviour of Electrohydraulic Servo System, Proceedings of $7^{\text {th }}$ IEEE International Symposium on Intelligent Systems and Informatics, Subotica, Serbia, 25-26 September, 2009, pp. 375-379

[18] A Kovari, D Fodor: ARX Model-based Fault Detection of Rolling Mill's Automatic Gauge Control System, Proceedings of $15^{\text {th }}$ IEEE International Power Electronics and Motion Control Conference, Novi Sad, Serbia, 4-6 September, 2012, pp. DS1d.6-1-DS1d.6-6

[19] Attila Kővári: Observer-based Leakage Detection of Hydraulic Cylinder Applied in Rolling Mills Electro-Hydraulic Gap Adjustment System, Materials Science, Testing and Informatics VI, Materials Science Forum, Vol. 729, 2013, pp. 424-429

[20] A Kovari, D Fodor: Identification-based Leakage Detection of Hydraulic Capsules, Proceeding of the $14^{\text {th }}$ IEEE International Symposium on Computational Intelligence and Informatics, Budapest, Hungary, 19-21 November, 2013, pp. 419-422

[21] Kevan Slater: Detecting and Managing Hydraulic System Leakage, Machinery Lubrication, 2001/7

[22] A Kovari: Dynamic Model of Rolling Mill's Electro-Hydraulic Gap Adjustment System, Materials Science, Testing and Informatics V, Materials Science Forum, Vol. 659, 2010, pp. 411-416 
[23] Besancon-Voda, A.: Iterative Auto-Calibration of Digital Controllers - a Systematic Design Approach and Case Study, Control Engineering Practice, Vol. 6, Num. 3, 1998, pp. 345-358

[24] Radu-Emil Precup, Stefan Preitl: PI and PID Controllers Tuning for Integral-Type Servo Systems to Ensure Robust Stability and Controller Robustness, Electrical Engineering, Vol. 88, Issue 2, 2006, pp. 149-156

[25] Samuel John, Jimoh O. Pedro: Neural Network-based Adaptive Feedback Linearization Control of Antilock Braking System, International Journal of Artifical intelligence, Vol. 10, Num. S13, 2013 